\title{
Remote Knowledge Acquisition and Assessment During the COVID-19 Pandemic
}

\author{
https://doi.org/10.3991/ijep.v10i6.16205 \\ Sébastien Jacques $(\bowtie)$ \\ University of Tours, Tours, France \\ sebastien.jacques@univ-tours.fr \\ Abdeldjalil Ouahabi \\ University of Bouira, Bouria, Algeria \\ University of Tours, Tours, France \\ Thierry Lequeu \\ University of Tours, Tours, France
}

\begin{abstract}
On 16 March 2020, as a result of the unprecedented global health crisis linked to the emergence of a new form of coronavirus (COVID-19), the 74 universities of France closed their doors, forcing nearly 1.6 million students, as well as their teachers, to find solutions and initiatives that could ensure continuity in teaching. In the reliance on videoconferencing tools, chat, the sharing of documents/tutorials/videos/podcasts, and the use of social networks, many ideas have emerged, but no consensus has developed nor has a common way of doing things been adopted by a majority of teachers. Some software tools, such as Zoom, have also been questioned over data security issues or excessive intrusion into the student learning process. Nevertheless, in these uncertain times, much had to be done so that students can acquire the requisite knowledge, develop skills, and build on what they have learned. How can we ensure that the learning process is as smooth as possible for everyone involved? How can we evaluate knowledge and skills learned at a distance, and their relevance? Four groups of electronic and electrical engineering students in France were monitored during the containment period in order to provide answers to these questions. Lectures, tutorials, practical work, and projects were carried out using the Microsoft Teams and Zoom video conferencing and chat tools to complement activities made available through the digital work environment. In order to ensure equity among all students, especially in view of the digital divide, open access tools/software/applications have been promoted. In the various surveys completed, the engineering students asserted their complete satisfaction with the learning process, the use of distance tools, and the level of mastery of these tools by their teachers. The results of the various knowledge tests show that, for the same course, distance learning does not reduce the performance of the engineering students. Indeed, they obtained local grades similar to those expected in face-to-face teaching. The results presented in this article are not intended to highlight the virtues of distance education, but rather to open up a debate and reflect more widely on the sustainability of this transformation of education in universities.
\end{abstract}

Keywords - COVID-19, Distance learning, Higher education, Synchronous elearning, Knowledge acquisition and assessment 


\section{Introduction}

Since the beginning of 2020, from one day to the next and from one side of the planet to the other, students around the world have seen their daily lives disrupted by the sudden appearance of an infectious disease caused by a strain of coronavirus (COVID19) - a disease that has affected tens of millions of people and has already caused the death of more than a million individuals [1-2]. Around the world, faced with the sudden closure of schools and universities (from the end of January 2020 in China and other Asian countries; mid-March in most countries of Europe, America and the Middle East; and the end of March in most African countries), teachers around the world have had to start teaching virtual courses, communicating with their students on social networking platforms, and, sometimes, learning on the job how best to deliver distance education [3-4].

In the face of this unprecedented health crisis, countries around the world have had to come up with an educational continuity plan that could be implemented as quickly as possible [5]. In the event of the temporary removal of pupils or the closure of schools, pedagogical continuity plans have sought to maintain the pedagogical connection between teachers and pupils, so as to preserve the knowledge already acquired by pupils while assisting in the acquisition of new knowledge [6]. As such, the stakes are high and there is a need to provide quality education, despite the many difficulties associated with distance learning. These include, but are not limited to, issues relating to: physical distance and socio-emotional support; support for students who are at risk of dropping out; the successful mastery of information and communication technologies (ICT); access to a stable and secure Internet connection; and access to appropriate computer equipment (e.g., computers, tablets, smart phones, etc.) [7]. On this latter point, according to the Organization for Economic Cooperation and Development (OECD), $95 \%$ of students in Switzerland, Norway and Austria have a computer on which they can do their schoolwork; in contrast, only $34 \%$ of Indonesian students have access to such a device [8-10].

Thanks to the mobilization and commitment of teaching and administrative personnel, the vectors and tools used by educational teams have multiplied. These tools have included: websites; digital workspaces (DWS); email discussion lists; document sharing and homework management applications; group registrations for interactive applications; Padlet-type collaborative walls and other multimedia creation tools; videos; radio podcasts and online tutorials; and pedagogical challenges given via social networks (e.g., Facebook, Twitter) [11-14].

Today, a multitude of applications, platforms and educational resources are being used in higher education. Many classifications using several categories have already been proposed in the literature. As such, the following list, with illustrative examples, is by no means exhaustive:

- Digital learning management systems: one example is the globally supported open learning platform MOODLE (with more than 60 partners in the Asia-Pacific region, Europe and the United Kingdom, America, and Africa) [15]. During the COVID-19 
pandemic, a wide range of activities (ranging from the simple submission of documents, to forums, online exercises, and online chat, etc.) have been offered to students [16].

- Massive open online course (MOOC) platforms, including iCourse (a platform offering courses in Chinese and English covering a wide range of disciplines including engineering, medicine, economics, arts and culture, etc.) [17-19]. This international MOOC platform, supported by 60 renowned Chinese universities, was launched in April 2020 by Higher Education Press in collaboration with NetEase Youdao. During the COVID-19 pandemic, nearly 200 higher education courses were offered free of charge to students around the world [20].

- Self-directed learning content: one example is Khan Academy's interactive platform, which, since 2008, has delivered thousands of online tutorials covering many scientific fields for use by undergraduate students. During the COVID-19 pandemic, students from all over the world were able to benefit from this platform [21].

- Collaboration platforms that support live-video communication: two good examples are Microsoft Teams and Zoom [22-23]. In fact, these two tools were widely deployed in the study presented in this article. Teams offers chat, dating, calling, and collaboration features built into Microsoft Office software. Zoom, which can be used as a Teams application, is a cloud-based platform offering video and audio conferencing, collaboration, chat, and webinars. Like the Proctorio platform, the use of Zoom in universities has raised many concerns, particularly in France, both about the confidentiality of the data that its shares and how such a tool is used, for example, for remote monitoring of exams.

Although the COVID-19 health crisis has highlighted the usefulness of digital technology in higher education, three key questions arise, which can be formulated as follows:

- How can we ensure that the knowledge presented through a distance learning course is of sufficient quality?

- How can we make the distance learning process as smooth as possible for all parties involved (i.e., students and teachers)? In particular, we feel that it is essential to take into account the issue of the digital divide, given the large number of students who do not necessarily have access to adequate computer equipment (e.g., differences in computer equipment, how best to take individual disabilities into account, etc.) [24].

- What are the best tools to assess knowledge and skills acquired at a distance and how can we ensure their relevance? For example, the organization of knowledge tests and examinations can be a real headache because of the need to choose appropriate assessment methods and numerical tools.

This article seeks to provide some answers to these questions. In particular, it presents a qualitative and quantitative assessment of the tools that have been put in place, in the context of the current global health crisis, with the aim of ensuring quality and continuity in higher education pedagogy. Feedback was provided through an assessment of students' knowledge and skills. To this end, several groups of about ten students in the field of electronic and electrical engineering in France were followed over 
the course of several months. These groups of engineering students participated in three technical courses and one mathematics course. The objective was to discuss the evaluation of the knowledge and skills acquired by the students at a distance. To this end, using classes of equivalent size, we compared the distributions of student results obtained through face-to-face and distance education courses. Finally, the feelings of these student groups were analyzed at the end of the set distance learning period. The ultimate aim of this article is not to extol the virtues of distance education, but to open up a debate and reflect on the sustainable and widely accepted transformation of teaching in universities [25].

The structure of this article is as follows. Section 2 presents a review of the literature on distance education. The purpose of this section is not only to position our work in relation to what has already been published in the literature, but also to identify the main advantages and disadvantages of digital learning management systems (i.e., CELENE) and collaboration platforms (i.e., Microsoft Teams and Zoom) with respect to the acquisition and evaluation of knowledge at a distance. Section 3 presents the methodological aspects of the study. Firstly, the defining characteristics of the student groups are presented. Then, the lessons selected as part of this feedback and their objectives are described. Finally, the method put in place to ensure the effective acquisition and evaluation of knowledge and skills at a distance is explained. Section 4 presents the main results and discusses the relevance of the proposed approach.

\section{$2 \quad$ Literature Review}

In this section, published reactions to distance education in universities are analyzed and the potential of two digital platforms - Microsoft Teams and Zoom—are assessed.

\subsection{The state of the art of distance education in universities}

Experiences recently reported in the literature show that interaction between students and teachers, as well as between students themselves, is more important in a virtual format than in a face-to-face format [23, 26-28]. The authors further explain that the main reason for this difference, in terms of successful learning and teaching, is that students may feel less shy about asking questions when they are separated by the barrier of a computer tool. Some authors also point out that distance learning can significantly reduce absenteeism. However, some forms of teaching, such as practical and project work, which require specific laboratory equipment, do not lend themselves well to distance learning. These authors also point out that, in such cases, the quality of human interaction in a physical classroom is difficult to match in virtual environments.

Despite the many positive points made about it, a number of authors indicate that the teaching style of virtual education must necessarily make use of various innovative methodologies to fully involve students and help them achieve the main pedagogical objectives, namely successful learning and the acquisition of relevant skills. The effort required by teachers to design effective virtual classrooms is very great and takes much more time than in the case of face-to-face teaching. 
Another extremely important point addressed in the literature concerns the management of knowledge assessments and measurement of class participation and attendance. In both face-to-face and distance learning, teachers need effective ways to measure their students' performance. This is usually done through the submission of homework, the administration of tests, exams and quizzes, and the creation of participation points. In a distance learning environment, table-top examinations and classroom participation and "attendance" are more difficult to measure.

In conclusion, distance education is not new-many prestigious universities around the world (e.g., in the USA, Europe, the United Kingdom, China, India, Australia, South Korea, Malaysia, and South Africa) have been practicing it for many years. What is new, however, is the extent to which universities are using collaborative digital platforms and online resources to teach both synchronously and asynchronously while ensuring their students remain motivated.

\subsection{Feedback on the use of Microsoft teams and zoom in higher education}

Although they were initially intended for business applications, Microsoft Teams and Zoom have both been used in recent years and are contributing to the current transformation of higher education [23], [29-33].

Microsoft Teams, available on its own or as part of an Office 365 package, is a customizable collaborative platform that integrates many features, including: video conferencing; scheduling team meetings via Microsoft Outlook, as well as sharing contacts and emails; file storage and transfer with SharePoint; and note-taking using OneNote. Many applications, such as Forms and Zoom, can be directly integrated into the tool [34].

The Zoom video communication tool provides a remote conferencing service that combines video conferencing, online meetings, chat, and mobile collaboration using proprietary applications. This tool has pedagogical potential as it allows the creation of a virtual room accessible to a large number of participants and offers many features useful in the realization of an online course, including: the creation of a videoconference for a large number of participants; the ability to record a videoconference and chat, allowing students to learn at their own pace; audio and chat interactions; screen sharing with teachers; as well as content sharing, real-time co-notation, and digital whiteboard [35].

Long before the health crisis caused by COVID-19, many authors were already emphasizing the integration into education of technological innovations in networking and communication. Microsoft Teams enables the creation of rich and functional learning environments where students play a proactive and constructive role throughout the learning process, as well as in/during all interactions in fully interactive computer-supported collaborative learning (CSCL) environments [30]. Its use has become even more visible during the COVID-19 outbreak, allowing us also to test the robustness of computer networks [36]. Despite this, the use of Microsoft Teams is still in its infancy, especially in higher education. Crawford et al. point out that, with regard to the assessment of knowledge and skills, further study is needed to ensure that distance education does not degrade student performance [12]. To this end, it is necessary to compare, for 
a given program of study and with classes of equivalent size, the performance of students in face-to-face and distance education. This is the primary motivation for the work presented in this article.

The Zoom platform has been used by many universities around the world during the COVID-19 epidemic. This Californian application has seen its number of downloads increase enormously since March 2020. Nevertheless, it is now being criticized over its lack of security and shortcomings in terms of personal data protection [37]. For example, on March 26, 2020, the American media outlet Vice revealed that the iOS version (Apple's operating system) of the application had, until recently, been sharing some of its users' personal data with Facebook without informing them-a practice that the company immediately assured it had put an end to. Over the same period, the NGO Access Now asked Zoom to publish a "transparency report" on its policy for managing and sharing user information.

These examples have not prevented prestigious universities, such as Harvard, Princeton, and Stanford, from generalizing the use of Zoom for all their students, in particular because of its simplicity and user-friendliness [38].

In France, its use seems less systematic. On a case-by-case basis, it is often left to the discretion of teachers to work with the tool that suits them best, particularly in classes preparing students for university entry. However, Zoom is clearly highlighted on the social networks of certain institutions, including NEOMA Business School, the University of Evry, and EM Normandie Business School.

The choice of a distance learning tool relies on the balancing of sometimes contradictory criteria, including: efficiency, quality of service, data protection, parameterization possibilities for different types of user, user ergonomics, and cost.

Despite some of the controversy described above, in the study presented article the Zoom application was used as a complement to Microsoft Teams because it has simple and modern digital ergonomics, allowing easy adoption by users. The application does not require any specific prior installation (a link is sent directly by the teacher to his/her students). Students can interact in virtual rooms, both from their computer and from their tablet or smartphone. This makes it possible to satisfy all our student-engineers, especially those who do not have a personal computer. Students also have the option of communicating via instant messaging, in addition to attending meetings held via video conferencing. For teachers, the platform offers various collaboration features, including: screen sharing for PowerPoint presentations, file sharing, and interactive whiteboard management.

Finally, in this study we sought to experiment with the use of these tools to conduct written examinations at a distance. As such, we ensured that all necessary measures to protect personal and/or sensitive data were taken. 


\section{Materials and Methods}

\subsection{Characteristics of the students participating in this study}

The research presented in this article was carried out with the participation of 63 students of electrical and electronic engineering in the College of Engineering of the University of Tours, France. For nearly three years, this engineering specialty has integrated two distinct curricula: one in embedded electronics for medical devices and the other in electronics and electrical energy systems [39]. Splitting the electrical and electronic engineering specialty has the advantage of placing students in small groups (each curriculum has a maximum of twenty engineering students). The objective of both curricula is to train future engineers in the in-depth understanding and design of electronic systems based on a solid mastery of appropriate technologies. In short, this engineering training program combines electronics, electrical energy (production, transport, distribution and storage), embedded systems (connected, autonomous, mobile), and smart/micro grids (smart grid, Internet of Things).

A total of 63 first- and second-year engineering students, divided into four groups (see Table 1), participated in this study. Before starting the experiment, a survey was sent out to the students. The objective was to discover the proportion of engineering students with sufficient computer equipment and software to follow the various courses through distance learning.

The results in Table 1 show that about $8 \%$ of the students felt that they did not have adequate computer equipment (e.g., personal computers, shared computers, graphic tablets, and smartphones) to comfortably follow these courses at a distance. In addition, just over $6 \%$ of the students surveyed felt that they lacked much of the software needed to participate in these distance education courses. In France, the National Office of Student Engineers, which represents all 185,000 engineering students, conducted a survey on the management of the health crisis in schools [40]. Questions were asked about access to computer equipment and software resources. The results of this feedback show that the percentages at national level and those indicated in this article are in perfect agreement.

Table 1. Characteristics of the students participating in this study

\begin{tabular}{|l|c|l|c|c|}
\hline $\begin{array}{c}\text { Group } \\
\text { No. }\end{array}$ & $\begin{array}{c}\text { Number } \\
\text { of students }\end{array}$ & \multicolumn{1}{|c|}{ Student level } & $\begin{array}{c}\text { Number of students who } \\
\text { feel their computer } \\
\text { equipment is insufficient }\end{array}$ & $\begin{array}{c}\text { Number of students } \\
\text { who feel they do not } \\
\text { have appropriate soft- } \\
\text { ware }\end{array}$ \\
\hline Group 1 & 9 & $4^{\text {th }}$-year university students & 1 & 0 \\
\hline Group 2 & 9 & $4^{\text {th }}$-year university students & 1 & 0 \\
\hline Group 3 & 16 & $4^{\text {th }}$-year university students & 1 & 2 \\
\hline Group 4 & 29 & $3^{\text {rd }}$-year university students & 2 & 2 \\
\hline
\end{tabular}




\subsection{Course selection and primary objectives}

Four courses were selected for this feedback process (see Table 2). Group 1 and Group 2 took two courses, respectively entitled "Reliability of Components and Systems" and "Thermomechanics of Power Devices", both in the field of engineering sciences. These two courses test the competency: "Capacity for analysis and synthesis explicitly mobilizing knowledge and understanding of a broad field of the basic sciences". For the subject "Reliability of components and systems", students must be able to master mathematical tools and methods related to probability and statistics. In the second course ("Thermomechanics of Power Devices"), engineering students must master the fundamental concepts of physics (i.e., electrical, mechanical, and thermal).

Table 2. Course selection and target competencies.

\begin{tabular}{|c|c|c|c|}
\hline Course name & $\begin{array}{l}\text { Student } \\
\text { group No. }\end{array}$ & Hourly teaching volume & Target competency \\
\hline $\begin{array}{l}\text { Reliability of devices and } \\
\text { systems }\end{array}$ & Group 1 & $\begin{array}{l}10 \text { hours of lectures } \\
10 \text { hours of tutorials } \\
8 \text { hours of practical work }\end{array}$ & \multirow{2}{*}{$\begin{array}{l}\text { Capacity for analysis and synthesis } \\
\text { explicitly mobilizing knowledge and } \\
\text { understanding of a broad field of the } \\
\text { basic sciences }\end{array}$} \\
\hline $\begin{array}{l}\text { Thermomechanics of } \\
\text { power devices }\end{array}$ & Group 2 & $\begin{array}{l}6 \text { hours of lectures } \\
8 \text { hours of tutorials } \\
12 \text { hours of practical work }\end{array}$ & \\
\hline Numerical analysis & Group 3 & $\begin{array}{l}4 \text { hours of lectures } \\
32 \text { hours of practical work }\end{array}$ & $\begin{array}{l}\text { Mastery of transverse engineering } \\
\text { methods and tools }\end{array}$ \\
\hline Project & Group 4 & 28 hours of project & $\begin{array}{l}\text { Ability to mobilize the resources of a } \\
\text { specific scientific and technical field }\end{array}$ \\
\hline
\end{tabular}

Group 3 students took a numerical analysis course to test the competency: "Mastery of transverse engineering methods and tools". The specific objective is to be able to model and solve even unfamiliar and/or incompletely defined problems using appropriate computer tools (here, for example, the MATLAB software package).

The engineering students in Group 4 carried out a project to design and build an electronic system for audio applications. The competency tested concerns the ability to mobilize the resources of a specific scientific and technical field. Faced with the unprecedented health situation, engineering students did not have access to the school premises, let alone all the equipment needed to design their final product. As a result, we focused their attention on applying an analytical approach to the design of the architecture of such an electronic system.

\subsection{Methodology for the acquisition and evaluation of knowledge at a distance}

Figure 1 illustrates the approach of remote knowledge acquisition and assessment taken in this article. This approach has four phases:

- Phase 1: Preparing students for distance learning.

- Phase 2: The actual learning phase, during which pupils are expected to acquire knowledge, develop skills, and build on their achievements.

- Phase 3: Assessment of knowledge and skills.

- Phase 4: Student evaluation of the distance learning experience. 


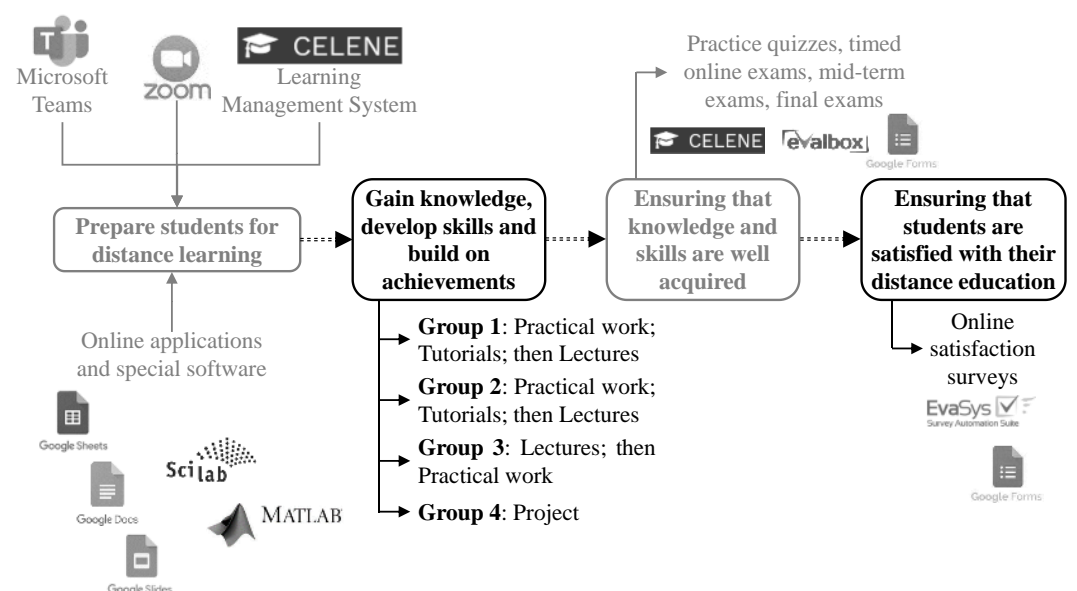

Fig. 1. The method of remote knowledge acquisition and assessment

In Phase 1, the objective was to prepare students for education through distance learning. The University of Tours asked its students to create Microsoft Teams accounts. The three teachers involved in this study only had to distribute them in their teaching activities. However, as shown in Table 1, some students were not able to use a computer. For this reason, we used the Zoom application, which does not require any installation - a link is simply sent to the students. As a result, the few students concerned were able to follow all teaching activities via their smartphones.

We also chose to use Google Drive tools (sheets, documents, and slides). Google Drive's cloud computing capabilities were taken advantage of because the use of digital work environments was particularly important during the containment period and it made sharing documents much easier. The objective was to provide access to (nonsensitive) documents to all students in the four groups so that they could work collaboratively/cooperatively. Teachers and students were able to download, share, comment on, and edit these documents. The teachers were able to follow the progress of their students' work, insert comments, correct exercises/practical work/study cases, and track each student's participation in the teamwork process. As far as practical work is concerned, students in groups 1, 2 and 3 limited them-selves to the mathematical modelling of multi-physical systems. As such, the engineering students used the open source multi-platform numerical computation soft-ware Scilab (a free and open source alternative to MATLAB). As for the organization of the projects, the students in Group 4 carried out a functional analysis of the electronic audio system proposed by the teacher. They used the Google Drive and Gantt Project tools to organize all the tasks, as well as the different milestones and deliverables. No experimental tests could be carried out as the students did not have access to the required laboratory equipment.

In phase 2, the students in groups 1 and 2 were able to put into practice a pedagogical approach, recently published in the literature, which sees the reversal of the traditional pedagogical sequence "Lectures; Tutorials; then Practical Work" [41]. This experience allowed us to verify, once again, that this pedagogical approach helps re-energize the 
student learning experience, as students can sometimes feel overwhelmed by the traditional university approach, which is very transmission-focused.

The students in Group 3 followed a traditional academic approach, although the number of lectures (i.e., 4 hours) was low in order to give them more practical work (i.e., 32 hours). While a two-hour lecture can work when delivered in person, the same in a distance course is not the best way to stimulate students, especially if many students are taking it through videoconferencing. To overcome these problems, the lectures were divided into mini-courses of about 20 minutes each (the free version of Zoom, limited to 40 minutes of videoconferencing, makes this possible) to make them more digestible. Finally, these mini-video courses were animated in the form of a TED (Technology, Entertainment and Design) conference. For students who did not have a strong Internet connection, the video conferences were recorded so that they could review them if necessary.

The Group 4 students had two study phases during their project. In the first phase, they were asked to perform a functional analysis of an electronic system (the target application was audio). The functional approach, in the definition of such an electronic system, implements an inductive reasoning of cause and consequence type, which requires, before any diagnosis or search for a solution is undertaken, the definition of the objectives.

For students, especially in the first year of engineering school, the pedagogical contribution is strong insofar as functional analysis is part of a rational approach to the construction of knowledge and know-how. In this first phase, the activity was organized around a logbook via the sharing tools in Google Drive. Here, we used chat rather than videoconferencing to encourage exchanges between students, as well as between teachers and engineering students. This format is certainly dynamic and allows a project to move forward fairly quickly. However, it requires the teacher to be extremely attentive and reactive. In the second phase of the project, we worked on writing a project report. An explanatory note was written by the teachers. With the help of videoconferencing, this manual was applied to two examples of documents written by students from previous classes. The chat was then used to provide ad hoc assistance in the drafting of the necessary documents and to answer final questions.

Concerning the evaluation of the knowledge and skills acquired by the students (phase 3), this is clearly the phase that raised the most questions, including: how to evaluate knowledge at a distance? How to ensure equity among students in terms of access to hardware and software resources? How to avoid cheating? And how to prevent the technology from being too intrusive? These are all questions that deserve further reflection, which we do not pretend to provide here. In this article, some initial quantitative elements are given concerning the tools that were hastily put in place in response to the pressing public health situation.

For Group 4, the work was simple. In their digital work environment, students had a drop box to hand in their project report at a date set by the teachers. If the drop box was difficult to access or use, students also had the option of sending their work by email.

For students in Group 3, it was exactly the same as before, with the only difference being that there were several drop boxes, as the students had to give their professors several reports on their practical work. 
For groups 1 and 2, two types of assessment were used, including a regular knowledge review and a final exam. Ongoing assessment of knowledge was carried out using self-correcting online questionnaires (at the time of correction, students were provided with details of expected responses for each question). The digital work environment was favored, but a backup was provided with the free software Evalbox and/or Google Forms in case the computer network was overloaded. At the end of the online quizzes, a chat session was scheduled to answer students' questions. The final review was more complicated to organize in view of the issues mentioned above. The teachers then experimented with two ways of proceeding. In the first they asked students to join a virtual room and compose a response on a topic with a time limit. At the end of the exam, students were given extra time to scan their paper and then send it by email. This first experience was not entirely satisfactory. Even though the teacher could take control of each participant's camera, it was impossible to manage the students without a smartphone connection to the virtual room. In addition, students complained about the intrusiveness of the approach and the lack of trust it generated. The approach in the second experiment was better accepted by the students because it was less intrusive and based on trust. In this approach they were given a time-limited task, but without connection to a virtual room. The subject was sent to them by email (with a backup via Google Drive). With extra time compared to the specified exam duration, students had to scan their work and drop it in a specific drop box or send it by email.

In Phase 4, students had the opportunity to evaluate the quality of the distance education courses. This not only allowed for an assessment of the quality of the training offer, but also strengthened communication with students, who always require a high level of interaction. This type of evaluation has been implemented by the University of Tours for many years. The EvaSys software platform is used to save considerable time at all stages of the evaluation process, including survey design and the distribution, reporting and accuracy checking of the automatically generated data. However, the questionnaire used at the end of a traditional training course was not fully adapted to distance education. For this reason, Google Forms was used to create a questionnaire, based on the existing format used at the university, but supplemented with questions on distance education, especially in cases where the teachers had not been able to foresee all the tools necessary to ensure the desired standard in their delivery (as has been the case in the COVID-19 pandemic).

\section{$4 \quad$ Main Results and Discussion}

\subsection{Comparison of student performance in face-to-face and distance education}

Figure 2 compares the student performance in face-to-face and distance education. Using a radar-type diagram, we can easily compare the performance of the four groups of engineering students presented in Table 1 who received distance education (see the solid black line in each graph in Figure 2) to a class of students of equivalent size who received the same course face-to-face (see the dashed grey line in each graph of Figure 2). 
For each of the four graphs in Figure 2, the performance of the students is reflected in the distribution of their local scores (from 0 to 20 , with 0 being the lowest score and 20 the highest). The radar diagrams show how homogeneous the distribution of the students' scores are around a circle of the same size (describing a trajectory as circular as possible). It is important to take note of the relevance of the approach used here: the levels of the students, before the start of the courses, were almost equivalent for both distance and face-to-face teaching.

Regardless of group, Figure 2 shows that distance education does not affect the performance of engineering students.

For groups 1 and 2, who used a teaching method that sees the reversal of the traditional pedagogical sequence "Lectures; Tutorials; then Practical Work", distance education does not alter the authors' conclusions [41].

The results in Figure 2 also show that for some groups (e.g., Group 3), distance education helped to smooth out the distribution of results (i.e., the trajectory described is more circular).

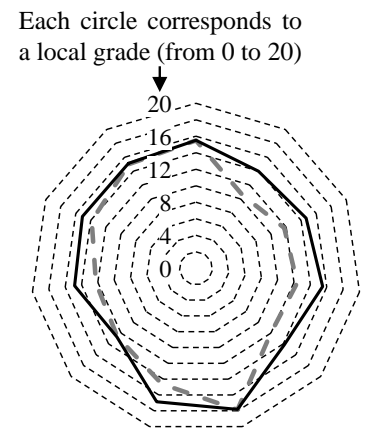

a) Group 1 (9 students)

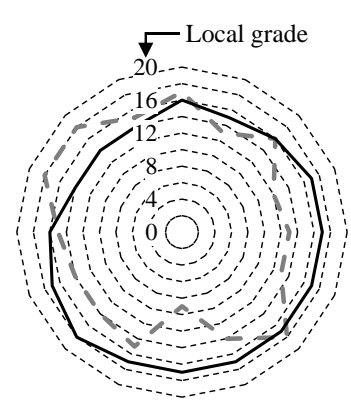

c) Group 3 (16 students)

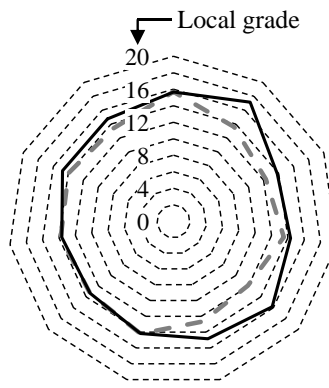

b) Group 2 (9 students)

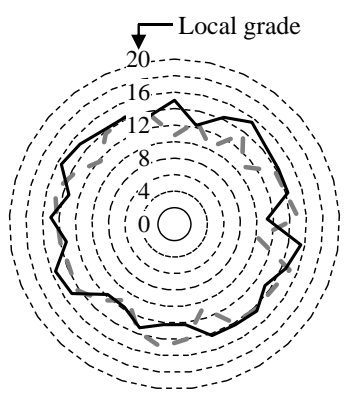

d) Group 4 (29 students)

\section{Caption for each radar diagram:}

— Distance learning

- - - Face-to-face learning (previous results on cohorts of equivalent size)

Fig. 2. Comparison of student performance in face-to-face and distance education: a) Group 1 (9 students); b) Group 2 (9 students); c) Group 3 (16 students); d) Group 4 (29 students) 


\subsection{Students' feelings about the proposed approach}

To complete this study, we asked all students in each group, through a satisfaction survey, to evaluate the quality of their distance education. An anonymous online form, based on what the University of Tours uses with the EvaSys platform, was proposed to them. Of course, this form had to be adapted because the questions usually used only lend themselves to face-to-face teaching. The questions asked concerned the teaching itself (e.g., clarity of the curriculum; prerequisites; content; selected illustrations), its organization (e.g., coordination between pedagogical activities; preparation for assessment of knowledge), the teacher (e.g., dynamism; mastery of distance learning tools; teacher-student interactions) and overall student satisfaction.

Table 3 shows the satisfaction survey results for all groups of engineering students.

Table 3. Example of satisfaction survey results: The results for the first group ( 9 students completed the survey), the second group ( 9 students completed the survey), the third group (16 students completed the survey), and the fourth group ( 29 students completed the survey) are shown in black, blue, green, and gray respectively

\begin{tabular}{|c|c|c|c|c|c|}
\hline Question & \begin{tabular}{|c|}
$\begin{array}{c}\text { Completely } \\
\text { agree }\end{array}$ \\
\end{tabular} & Agree & Disagree & $\begin{array}{c}\text { Disagree } \\
\text { completely }\end{array}$ & \begin{tabular}{|c|}
$\begin{array}{c}\text { Satisfaction } \\
\text { score }\end{array}$ \\
\end{tabular} \\
\hline $\begin{array}{l}\text { 1. The syllabus for this teaching was } \\
\text { clearly presented. }\end{array}$ & $\begin{array}{c}100.0 \% \\
100.0 \% \\
81.3 \% \\
72.4 \% \\
\end{array}$ & $\begin{array}{c}0.0 \% \\
0.0 \% \\
18.8 \% \\
27.6 \% \\
\end{array}$ & $\begin{array}{l}0.0 \% \\
0.0 \% \\
0.0 \% \\
0.0 \% \\
\end{array}$ & $\begin{array}{l}0.0 \% \\
0.0 \% \\
0.0 \% \\
0.0 \% \\
\end{array}$ & $\begin{array}{c}100.0 \% \\
100.0 \% \\
95.3 \% \\
93.1 \% \\
\end{array}$ \\
\hline $\begin{array}{l}\text { 2. The prerequisites for this teaching } \\
\text { were clearly presented. }\end{array}$ & $\begin{array}{l}66.7 \% \\
88.9 \% \\
75.0 \% \\
72.4 \% \\
\end{array}$ & $\begin{array}{l}33.3 \% \\
11.1 \% \\
25.0 \% \\
27.6 \% \\
\end{array}$ & $\begin{array}{l}0.0 \% \\
0.0 \% \\
0.0 \% \\
0.0 \% \\
\end{array}$ & $\begin{array}{l}0.0 \% \\
0.0 \% \\
0.0 \% \\
0.0 \% \\
\end{array}$ & $\begin{array}{l}91.7 \% \\
97.2 \% \\
93.8 \% \\
93.1 \% \\
\end{array}$ \\
\hline $\begin{array}{l}\text { 3. The content of this teaching was } \\
\text { adapted to your knowledge. }\end{array}$ & $\begin{array}{l}88.9 \% \\
55.6 \% \\
75.0 \% \\
65.5 \% \\
\end{array}$ & $\begin{array}{l}11.1 \% \\
44.4 \% \\
25.0 \% \\
31.0 \% \\
\end{array}$ & $\begin{array}{l}0.0 \% \\
0.0 \% \\
0.0 \% \\
3.5 \% \\
\end{array}$ & $\begin{array}{l}0.0 \% \\
0.0 \% \\
0.0 \% \\
0.0 \% \\
\end{array}$ & $\begin{array}{l}97.2 \% \\
88.9 \% \\
93.8 \% \\
90.5 \% \\
\end{array}$ \\
\hline $\begin{array}{l}\text { 4. This teaching was presented in a stim- } \\
\text { ulating and motivating manner. }\end{array}$ & $\begin{array}{l}77.8 \% \\
66.7 \% \\
43.8 \% \\
48.3 \%\end{array}$ & $\begin{array}{l}22.2 \% \\
33.3 \% \\
50.0 \% \\
20.7 \%\end{array}$ & $\begin{array}{c}0.0 \% \\
0.0 \% \\
6.2 \% \\
31.0 \%\end{array}$ & $\begin{array}{l}0.0 \% \\
0.0 \% \\
0.0 \% \\
0.0 \%\end{array}$ & $\begin{array}{l}94.5 \% \\
91.7 \% \\
84.4 \% \\
79.3 \%\end{array}$ \\
\hline $\begin{array}{l}\text { 5. Coordination between lectures, tutori- } \\
\text { als and practical work was not difficult. }\end{array}$ & $\begin{array}{l}88.9 \% \\
66.7 \% \\
43.8 \% \\
69.0 \% \\
\end{array}$ & $\begin{array}{l}11.1 \% \\
33.3 \% \\
50.0 \% \\
31.0 \% \\
\end{array}$ & $\begin{array}{l}0.0 \% \\
0.0 \% \\
6.2 \% \\
0.0 \% \\
\end{array}$ & $\begin{array}{l}0.0 \% \\
0.0 \% \\
0.0 \% \\
0.0 \% \\
\end{array}$ & $\begin{array}{l}97.2 \% \\
91.7 \% \\
84.4 \% \\
92.2 \% \\
\end{array}$ \\
\hline $\begin{array}{l}\text { 6. Illustrations (i.e., exercises, case stud- } \\
\text { ies and practical work) were sufficient. }\end{array}$ & $\begin{array}{c}100.0 \% \\
66.7 \% \\
43.8 \% \\
48.3 \% \\
\end{array}$ & $\begin{array}{c}0.0 \% \\
33.3 \% \\
56.2 \% \\
51.7 \% \\
\end{array}$ & $\begin{array}{l}0.0 \% \\
0.0 \% \\
0.0 \% \\
0.0 \% \\
\end{array}$ & $\begin{array}{l}0.0 \% \\
0.0 \% \\
0.0 \% \\
0.0 \% \\
\end{array}$ & $\begin{array}{l}100.0 \% \\
91.7 \% \\
85.9 \% \\
87.1 \% \\
\end{array}$ \\
\hline $\begin{array}{l}\text { 7. Instructions for preparing knowledge } \\
\text { assessments were clear. }\end{array}$ & $\begin{array}{c}100.0 \% \\
88.9 \% \\
75.0 \% \\
72.4 \% \\
\end{array}$ & $\begin{array}{c}0.0 \% \\
11.1 \% \\
25.0 \% \\
27.6 \% \\
\end{array}$ & $\begin{array}{l}0.0 \% \\
0.0 \% \\
0.0 \% \\
0.0 \% \\
\end{array}$ & $\begin{array}{l}0.0 \% \\
0.0 \% \\
0.0 \% \\
0.0 \% \\
\end{array}$ & $\begin{array}{l}100.0 \% \\
97.2 \% \\
93.8 \% \\
93.1 \% \\
\end{array}$ \\
\hline $\begin{array}{l}\text { 8. You have been well prepared for the } \\
\text { various knowledge assessments proposed } \\
\text { by your teacher. }\end{array}$ & $\begin{array}{l}66.7 \% \\
55.6 \% \\
43.8 \% \\
44.8 \%\end{array}$ & $\begin{array}{l}33.3 \% \\
44.4 \% \\
43.8 \% \\
55.2 \%\end{array}$ & $\begin{array}{c}0.0 \% \\
0.0 \% \\
12.4 \% \\
0.0 \%\end{array}$ & $\begin{array}{l}0.0 \% \\
0.0 \% \\
0.0 \% \\
0.0 \%\end{array}$ & $\begin{array}{l}91.7 \% \\
88.9 \% \\
82.8 \% \\
86.2 \%\end{array}$ \\
\hline
\end{tabular}


Paper-Remote Knowledge Acquisition and Assessment During the COVID-19 Pandemic

\begin{tabular}{|c|c|c|c|c|c|}
\hline $\begin{array}{l}\text { 9. The skills demonstrated by your } \\
\text { teacher are unquestionable, despite the } \\
\text { distance. }\end{array}$ & $\begin{array}{l}88.9 \% \\
55.6 \% \\
56.2 \% \\
62.1 \% \\
\end{array}$ & $\begin{array}{l}11.1 \% \\
44.4 \% \\
43.8 \% \\
37.9 \%\end{array}$ & $\begin{array}{l}0.0 \% \\
0.0 \% \\
0.0 \% \\
0.0 \%\end{array}$ & $\begin{array}{l}0.0 \% \\
0.0 \% \\
0.0 \% \\
0.0 \%\end{array}$ & $\begin{array}{l}97.2 \% \\
88.9 \% \\
89.1 \% \\
90.5 \%\end{array}$ \\
\hline $\begin{array}{l}\text { 10. Despite the distance, your teacher } \\
\text { was available and listening. }\end{array}$ & $\begin{array}{l}88.9 \% \\
88.9 \% \\
62.5 \% \\
69.0 \% \\
\end{array}$ & $\begin{array}{l}11.1 \% \\
11.1 \% \\
37.5 \% \\
31.0 \% \\
\end{array}$ & $\begin{array}{l}0.0 \% \\
0.0 \% \\
0.0 \% \\
0.0 \% \\
\end{array}$ & $\begin{array}{l}0.0 \% \\
0.0 \% \\
0.0 \% \\
0.0 \% \\
\end{array}$ & $\begin{array}{l}97.2 \% \\
97.2 \% \\
90.6 \% \\
92.2 \%\end{array}$ \\
\hline $\begin{array}{l}\text { 11. Your teacher seems to have mastered } \\
\text { digital tools at a distance. }\end{array}$ & $\begin{array}{l}55.6 \% \\
88.9 \% \\
75.0 \% \\
72.4 \%\end{array}$ & $\begin{array}{l}44.4 \% \\
11.1 \% \\
25.0 \% \\
27.6 \%\end{array}$ & $\begin{array}{l}0.0 \% \\
0.0 \% \\
0.0 \% \\
0.0 \%\end{array}$ & $\begin{array}{l}0.0 \% \\
0.0 \% \\
0.0 \% \\
0.0 \% \\
\end{array}$ & $\begin{array}{l}88.9 \% \\
97.2 \% \\
93.8 \% \\
93.1 \%\end{array}$ \\
\hline $\begin{array}{l}\text { 12. Despite the distance, the interaction } \\
\text { between the teacher and students was } \\
\text { quite good. }\end{array}$ & $\begin{array}{l}66.7 \% \\
77.8 \% \\
56.3 \% \\
69.0 \% \\
\end{array}$ & $\begin{array}{l}33.3 \% \\
22.2 \% \\
25.0 \% \\
20.7 \% \\
\end{array}$ & $\begin{array}{l}0.0 \% \\
0.0 \% \\
18.7 \% \\
10.3 \% \\
\end{array}$ & $\begin{array}{l}0.0 \% \\
0.0 \% \\
0.0 \% \\
0.0 \% \\
\end{array}$ & $\begin{array}{l}91.7 \% \\
94.5 \% \\
84.4 \% \\
89.7 \% \\
\end{array}$ \\
\hline $\begin{array}{l}\text { 13. You are generally satisfied with the } \\
\text { quality of the education provided. }\end{array}$ & $\begin{array}{l}88.9 \% \\
66.7 \% \\
43.8 \% \\
44.8 \%\end{array}$ & $\begin{array}{l}11.1 \% \\
33.3 \% \\
56.2 \% \\
48.3 \%\end{array}$ & $\begin{array}{l}0.0 \% \\
0.0 \% \\
0.0 \% \\
6.9 \% \\
\end{array}$ & $\begin{array}{l}0.0 \% \\
0.0 \% \\
0.0 \% \\
0.0 \%\end{array}$ & $\begin{array}{l}97.2 \% \\
91.7 \% \\
85.9 \% \\
84.5 \%\end{array}$ \\
\hline
\end{tabular}

The results show an overall satisfaction rate of $92 \%$ (i.e., $95.7 \%$ for Group 1; $93.6 \%$ for Group 2; $89.1 \%$ for Group 3; and $89.6 \%$ for Group 4 ).

Despite these rather positive results, four issues raised questions from students in Groups 3 and 4: the dynamism of distance education; coordination of pedagogical activities; preparation for examinations; and interaction between students and teachers.

With regard to the dynamism of distance education (see Table 3, question 4), students found that some courses, particularly the project, did not really lend themselves to this format. This is not the responsibility of the teachers. The students pointed out here the inability to produce a finished product, even though they felt that a functional analysis was essential. Courses that require students to set up a system must therefore be conducted face-to-face.

The coordination of the different pedagogical activities (see Table 3, question 5) was also a point of discussion, a point that is not really the responsibility of the teachers involved in this study. Students pointed out the sometimes very busy agendas that mix many activities of the same nature during the same day.

For the assessment of knowledge and skills (see Table 3, question 8), only the final exams were questioned. Intrusive methods, involving the remote control of student materials, were very poorly perceived. The results of the survey show that students attach great importance to the trust that teachers place in them. An examination format where the student composes on a topic for a limited amount of time and the student has to hand in the assignment in a drop box seems to be a solution to be further explored.

In terms of interaction between students and between teachers and students (see Table 3 , question 12 ), the format of the 20-minute mini-courses was very well received; some students, sometimes shy in class, did not hesitate to participate and ask questions. The chat during the hands-on activities (practical work and project) was well appreciated by the students. Nevertheless, regardless of the group, students preferred the faceto-face in the practical/project work as they appreciated the closeness with their teachers. Thanks to these face-to-face exchanges, students can enrich themselves, build their 
own ideas and gain more maturity by confronting each other. Finally, the students indicated that in class, when a group deviates from a target objective, the teachers can put it back on track, which is much more difficult from a distance.

\section{Conclusion}

Since the beginning of 2020, in the face of the COVID-19 pandemic, which led to the widespread closure of universities, teaching teams across the world have striven to ensure pedagogical continuity for their students. The digital university has thus become a reality, but with no real consensus on pedagogical practice. In particular, three issues have arisen, concerning the quality of distance education compared to face-to-face teaching, the use of collaborative distance platforms to ensure the smooth running of the learning process, and, finally, the use of these tools to ensure the relevance of the assessment of students' knowledge and skills.

In this article, some answers - both qualitative and quantitative- to these research questions have been provided. To this end, four groups of students from an electronics and electrical engineering school in France were tracked throughout the process of "enforced" distance learning. Pedagogical forms, such as lectures and tutorials, were provided through the use of video conferencing, chat, the sharing of documents/tutorials/videos/podcasts, and the use of social networks. In particular, two collaborative platforms, Microsoft Teams and Zoom, were tested to complement the digital working environment of the engineering school (CELENE).

The results of the various knowledge tests show that, for the same course, distance learning does not reduce the performance of the engineering students. Indeed, they obtained local grades similar to those expected from face-to-face teaching.

For students with sufficient material resources and software (i.e., about $92 \%$ of the 63 students involved in this study), these forms of distance education presented little obstacle and were well appreciated. For the $8 \%$ of students affected by the digital divide, it was necessary to use telephone communications and social networks to ensure that their learning process was not affected. On the other hand, the four groups of students were much less enthusiastic about pedagogical forms requiring the implementation of electronic systems, i.e., during practical and project work. The results of the satisfaction surveys show that the students appreciate face-to-face education in these more "practical" forms of teaching for two main reasons. The first concerns the degree of socialization involved, with practical and project work being seen as moments of sharing and exchange between students, as well as between students and teachers. It is through this socialization that students develop their scientific and professional identities, acquire maturity, and, finally, prepare themselves for the reality of the field (the business world). The second concerns the role of the teacher in practical and project work. When a teacher is in the classroom with the students, he/she is able to sense the general state of mind, supervise the students, and rectify the situation if he/she feels that the expected results will not be achieved. Distance learning is much more difficult in this case because the teacher does not really receive immediate feedback and so cannot rapidly adapt his/her teaching methods. 
Although this initial feedback is positive, everything has been done in haste without any real consensus on teaching practices. In relation to the development of the "digital university", two important questions arise:

- How can the pressing need to facilitate a virtual teaching environment, as felt in an emergency situation, make sense in a more traditional (and less confined) teaching situation?

- How can teachers be best supported in relation to what they encounter in the field?

As the current health situation is far from over, the University of Tours has proposed to set up "hybrid solutions", spread over the academic year 2020-2021. To do this, teachers are going back and forth between face-to-face and distance learning phases, with the Microsoft Teams tool being the currently most widely deployed collaborative digital platform. Digital referents are also proposed. They constitute an essential link in the communication around digital education: technical and pedagogical assistance, training relays, institutional communication relays (proposal of training courses, tools), etc. At a distance, artificial intelligence is also a solution that may be worthy of study, for example to detect facial expression of emotion during the learning phases [42].

Finally, this article has shown that the question of how best to undertake evaluation of knowledge and learning at a distance is a real headache. Distance necessarily implies a relationship of trust with students because it is almost impossible to control the conditions under which individual work is carried out. Several approaches are currently being explored to help teachers assess student performance, including: stopping all assessment; focusing on self-assessment; developing a portfolio of skills to be acquired by the end of a course; and developing online quizzes (accessible via smartphones, tablets and computers) before the start of each course (e.g., the Wooclap tool has been made available by the University of Tours).

\section{References}

[1] Sohrabi C., Alsafi Z., O’Neill N., Khan M., Kerwan A., Al-Jabir A. et al. (2020). World Health Organization declares global emergency: A review of the 2019 novel coronavirus (COVID-19). International Journal of Surgery, 76, pp. 71-76. https://doi.org/10.1016/ j.ijsu.2020.03.036

[2] Remuzzi A., Remuzzi G. (2020). COVID-19 and Italy: what next? The Lancet, 395(10231), pp. 1225-1228. https://doi.org/10.1016/s0140-6736(20)30627-9

[3] Tran T., Hoang A.-D., Nguyen Y.-C., Nguyen L.-C., Ta N.-T., Pham Q.-H. (2020). Toward Sustainable Learning during School Suspension: Socioeconomic, Occupational Aspirations, and Learning Behavior of Vietnamese Students during COVID-19. Sustainability, 12(10), 4195. https://doi.org/10.3390/su12104195

[4] Viner R. M., Russell S. J., Croker H., Packer J., Ward J., Stansfield C. et al. (2020). School closure and management practices during coronavirus outbreaks including COVID-19: a rapid systematic review. The Lancet Child \& Adolescent Health, 4(5), pp. 397-404. https://doi.org/10.1016/s2352-4642(20)30095-x

[5] Reich J., et al. (2020). Remote Learning Guidance from State Education Agencies during the COVID-19 Pandemic: A First Look. Retrieved from osf.io/k6zxy/. Accessed on 1 May 2020. 
[6] Reimers F. M., Schleicher A. (2020) A framework to guide an education response to the COVID-19 Pandemic of 2020, available via https://teachertaskforce.org/sites/default/files/202004/A\%20framework\%20to\%20guide\%20an\%20education\%20response $\% 20$ to $\% 20$ the $\% 20$ COVID-19\%20Pandemic\%20of\%202020.pdf. Accessed on 1 June 2020

[7] Toquero C. M. (2020). Challenges and Opportunities for Higher Education amid the COVID-19 Pandemic: The Philippine Context. Pedagogical Research, 5(4), 5 p. https://doi. org $/ 10.29333 / \mathrm{pr} / 7947$

[8] Bol, T. (2020, April 30). Inequality in home schooling during the Corona crisis in the Netherlands. First results from the LISS Panel. https://doi.org/10.31235/osf.io/hf32q

[9] De Quervain D., Aerni A., Amini E., Bentz D., Coynel D., Gerhards C. et al. (2020, April 24). The Swiss Corona Stress Study. https://doi.org/10.31219/osf.io/jqw6a

[10] Yulia H. (2020). Online Learning to Prevent the Spread of Pandemic Corona Virus in Indonesia. ETERNAL (English Teaching Journal), 11(1), pp. 48-56. https://doi.org/10. 26877/eternal.v11i1.6068

[11] Sistek-Chandler C. M. (2020). Exploring Online Learning Through Synchronous and Asynchronous Instructional Methods. IGI Global. http://doi:10.4018/978-1-7998-1622-5.

[12] Crawford J., Butler-Henderson K., Rudolph J., Glowatz M. et al. (2020). COVID-19: 20 Countries' Higher Education Intra-Period Digital Pedagogy Responses. Journal of Applied Teaching and Learning (JALT), 3(1), pp. 1-20. https://doi.org/10.37074/jalt.2020.3.1.7

[13] Ebner M., Schön S., Braun C., Ebner M., Grigoriadis Y., Haas M. et al. (2020). COVID-19 Epidemic as E-Learning Boost? Chronological Development and Effects at an Austrian University against the Background of the Concept of "E-Learning Readiness". Future Internet, 12(6), 94. https://doi.org/10.3390/fi12060094

[14] Nonthamand N. (2020). Guideline to Develop an Instructional Design Model Using Video Conference in Open Learning. International Journal of Emerging Technologies in Learning (iJET), 15(3), pp. 140-155. https://doi.org/10.3991/ijet.v15i03.10842

[15] Ba M. L., Gueye B., Gueye A. D., Kassé O. (2019). Impacts of the Migration of CrossCutting Courses of a Traditional University in Distance Learning. International Journal of Engineering Pedagogy (iJEP), 9(2), pp. 51-64. https://doi.org/10.3991/ijep.v9i2.9945

[16] Putri S. E., Hamuddin B., Nursafira M. S., Derin T. (2020). Discourse Analysis in E-Learning-Based Course Using Moodle Platform: An Experimental Design. Journal of Research and Innovation in Language, 2(1), pp. 19-26. https://doi.org/10.31849/reila. v2i1.3960

[17] Mayende G., Prinz A., Isabwe G. M. N., Muyinda P. B. (2017). Learning Groups in MOOCs - Lessons for Online Learning in Higher Education. International Journal of Engineering Pedagogy (iJEP), 7(2), pp. 109-124. https://doi.org/10.3991/ijep.v7i2.6925

[18] Kefalis C., Drigas A. (2019). Web Based and Online Applications in STEM Education. International Journal of Engineering Pedagogy (iJEP), 9(4), pp. 76-85. https://doi.org/ 10.3991/ijep.v9i4.10691

[19] Ge J., Li X. (2019). Design Strategies of EFL Learning Videos: Exampled by a China MOOC. Proceedings of the 2020 9th International Conference on Educational and Information Technology (ICEIT 2020), February 2020, Oxford, UK, pp. 68-71. https://doi. org/10.1145/3383923.3383927

[20] Tiejun Z. (2020). Empirical Research on the Application of Online Teaching in Chinese Colleges and Universities Under the Situation of Novel Coronavirus Pneumonia Prevention and Control. International Journal of Emerging Technologies in Learning (iJET), 15(11), pp. 119-136. https://doi.org/10.3991/ijet.v15i11.13935

[21] Fazal N., Fadhil S., Edquiban M., Olk S. (2020). The Use of Moodle Apps and Khan Academy Short Videos to Engage Students to Learn Microbiology/Immunology. The Journal of Immunology, 204(1). 
[22] Henriksen D., Creely E., Henderson M. (2020). Folk Pedagogies for Teacher Transitions: Approaches to Synchronous Online Learning in the Wake of COVID-19. Journal of Technology and Teacher Education (JTATE), 28(2), pp. 201-209.

[23] Basilaia G., Kvavadze D. (2020). Transition to Online Education in Schools during a SARS -CoV-2 Coronavirus (COVID-19) Pandemic in Georgia. Pedagogical Research, 5(4), pp. 19. https://doi.org/10.29333/pr/7937

[24] Faustino P., \& Simões D. (2020). The Contribution of the Technology Acceptance Model for an Active Teaching and Learning Process in Higher Education: A Bibliometric Analysis. In Montebello, M. (Ed.), Handbook of Research on Digital Learning (pp. 242-261). IGI Global. https://doi.org/10.4018/978-1-5225-9304-1.ch015

[25] Polyakova T. (2020). Guest Editorial-Engineering Pedagogy: On the Way to "Education 4.0". International Journal of Engineering Pedagogy (iJEP), 10(4), pp. 4-7. https://doi.org/ 10.3991/ijep.v10i4.15021

[26] Auer M. E., \& Tsiatsos T. (2019). The Challenges of the Digital Transformation in Education: Proceedings of the 21st International Conference on Interactive Collaborative Learning (ICL2018) - Volume 1 (982 pages). Springer International Publishing. https://doi. org/10.1007/978-3-030-11935-5

[27] Hartnett M. (2020). Flexible and Distance Learning. In: Tatnall A. (eds) Encyclopedia of Education and Information Technologies. Springer, Cham. https://doi.org/10.1007/978-3030-10576-1_67

[28] Kurbakova S., Volokova Z., Kurbakov A. (2020). Virtual Learning and Educational Environment: New Opportunities and Challenges under the COVID-19 Pandemic. Proceedings of the 4th International Conference on Education and Multimedia Technology, pp. 167-171. https://doi.org/10.1145/3416797.3416838

[29] Hubbard M., Bailey M.J. (2018) User Adoption in Teams. In: Mastering Microsoft Teams. Apress, Berkeley, CA. https://doi.org/10.1007/978-1-4842-3670-3_5

[30] Martin L., Tapp D. (2019). Teaching with Teams: An introduction to teaching an undergraduate law module using Microsoft Teams. Innovative Practice in Higher Education, 3(3), pp. 58-66.

[31] Raffone A., Monti J. (2019). A Digital Storytelling Laboratory to Foster Second Language Acquisition in Higher Education: Students' Perspectives and Reflections. Proceedings of the 12th International Conference on Innovation in Language Learning, 14-15 November 2019, Florence, Italy, 91.

[32] Li H., Guo M. (2017). Application of Zoom in Multisensory Teaching from the Perspective of Multisensory Integration. Proceedings of the 2017 International Conference on Energy, Environment and Sustainable Development (EESD 2017), 21-22 April 2017, Phuket, Thailand, pp. 226-230. https://doi.org/10.12783/dteees/eesd2017/12005

[33] Beriswill J. (2018). Zoom Redefines Web Conferencing for Education. In Proceedings of ELearn: World Conference on E-Learning in Corporate, Government, Healthcare, and Higher Education (pp. 1208-1211). Las Vegas, NV, United States: Association for the Advancement of Computing in Education (AACE). Retrieved June 9, 2020 from https:// www.learntechlib.org/primary/p/185333/.

[34] Ilag B. N. (2018). Introducing Microsoft Teams: Understanding the New Chat-Based Workspace in Office 365. Tracy, California, USA: Apress. https://doi.org/10.1007/978-1-4842$\underline{3567-6}$

[35] Añel J.A. et al. (2020). Cloud and Serverless Computing for Scientists. Springer Nature Switzerland AG. http://doi:10.1007/978-3-030-41784-0

Favale T., Soro F., Trevisan M., Drago I., Mellia M. (2020). Campus traffic and e-Learning during COVID-19 pandemic. Computer Networks, 176, 107290. https://doi.org/10.1016 j.comnet.2020.107290 
[37] Jee C. Zoom is facing questions about how private or secure it really is, MIT Technology Review, available via https://www.technologyreview.com/2020/04/01/974992/zoom-is-facing-questions-about-how-private-or-secure-it-really-is/. Accessed on 1 April 2020.

[38] Kamenetz A. A Growing Number of U.S. Colleges Cancel Classes Amid Coronavirus Fears, National Public Radio, Inc. (US), available via https://www.npr.org/2020/03/09/813750481/ more-than-20-colleges-cancel-in-person-classes-in-response-to-coronavirus? $\mathrm{t}=15917810$ 89727. Accessed on 1 April 2020.

[39] Electronics \& Electrical Energy Systems in French, College of Engineering of the University of Tours (France), available via https://polytech.univ-tours.fr/programs/training-of-engineers/electronics-electrical-energy-systems/. Accessed on 10 May 2020.

[40] Survey COVID-19 in French, National Office of Student Engineers (France), available via https://www.bnei.fr/covid-19/. Accessed on 10 May 2020.

[41] Jacques S., Lequeu T. (2020). The Attractiveness of Reversing Teaching Forms, Feedback on an Electrical Engineering Course. International Journal of Engineering Pedagogy (iJEP), 10(3), pp. 21-34. https://doi.org/10.3991/ijep.v10i3.12361

[42] Adjabi I., Ouahabi A., Benzaoui A., Taleb-Ahmed A. (2020). Past, Present, and Future of Face Recognition: A Review. Electronics, 9(8), 1188. https://doi.org/10.3390/electron$\underline{\operatorname{ics} 9081188}$

\section{Authors}

Sébastien Jacques has been an Assistant Professor in the Electrical and Electronic Engineering Specialty at the College of Engineering of the University of Tours (France) since 2012. He has also been with the research group on materials, microelectronics, acoustics and nanotechnology (GREMAN UMR 7347, CNRS, INSA Centre Val-deLoire). His teaching and research activities focus on electronic systems and their reliability dedicated to smart cities. In parallel with all these activities, he is interested in the implementation of innovative teaching methods in universities.

Abdeldjalil Ouahabi is Full Professor at the University of Tours in France. He is currently leading a research team at the Department of Computer Science at the University of Bouira in Algeria. His research interests include Image and Signal Processing, Biomedical Engineering and Machine Learning. Prof. Ouahabi is the author of over 170 published papers in these areas and he is a member of the editorial board of several Web of Science journals. He has also served as General Chairman of various international conferences.

Thierry Lequeu has been working at the University of Tours (France) as a Senior Lecturer since 1996. His teaching and research activities are related to the conversion and management of electrical energy. In many power electronics projects, he has focused on the development of electric go-karts as multidisciplinary educational applications.

Article submitted 2020-06-15. Resubmitted 2020-10-19. Final acceptance 2020-10-19. Final version published as submitted by the authors. 